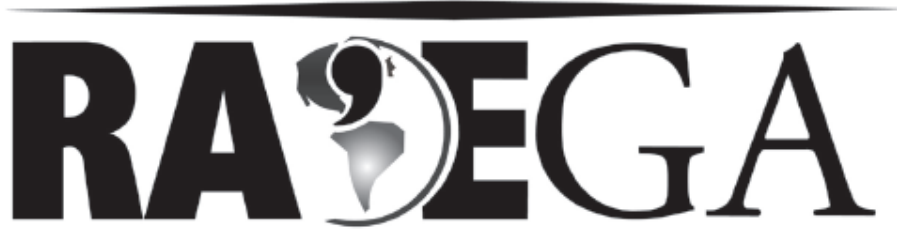

O ESPAÇO GEOGRÁFICO EM ANÁLISE

\title{
ANÁLISE TEMPORAL DO USO DO SOLO E COMPARAÇÃO ENTRE OS ÍNDICES DE VEGETAÇÃO NDVI E SAVI NO MUNICÍPIO DE SANTA CRUZ DO RIO PARDO - SP USANDO IMAGENS LANDSAT-5
}

\section{Temporal analysis of the land use and comparison between NDVI and SAVI indexes in the city of Santa Cruz do Rio Pardo - SP using Landsat-5 images}

\author{
Julio Cesar DEMARCHI ${ }^{1}$ \\ Edson Luís PIROLI ${ }^{2}$ \\ Célia Regina Lopes ZIMBACK ${ }^{3}$
}

\section{RESUMO}

Este trabalho objetiva analisar a evolução temporal do uso do solo no município de Santa Cruz do Rio Pardo - SP por meio da classificação supervisionada de imagens de satélite Landsat-5 TM por máxima verossimilhança, bem como verificar a exatidão do mapeamento através do índice Kappa, comparar os índices de vegetação NDVI e SAVI em diferentes fatores de ajuste para o substrato do dossel e determinar a porcentagem de

\footnotetext{
${ }^{1}$ Licenciado e bacharel em Geografia. Aluno do Programa de Pós-Graduação em Agronomia (Energia na Agricultura) da Faculdade de Ciências Agronômicas da Unesp - Campus de Botucatu. E-mail: julio.demarchi@gmail.com

${ }^{2}$ Engenheiro Florestal. Professor Assistente Doutor do curso de graduação em Geografia da Unesp Campus Experimental de Ourinhos e do Programa de Pós-Graduação em Geografia da Faculdade de Ciências e Tecnologia da Unesp - Campus de Presidente Prudente. E-mail: elp@ourinhos.unesp.br

${ }^{3}$ Engenheira Agrônoma. Professora Adjunta do Departamento de Recursos Naturais - Ciência do Solo da Faculdade de Ciências Agronômicas da Unesp - Campus de Botucatu. E-mail: czimback@gmail.com
} 
cobertura vegetal em todos os métodos utilizados, nas datas 26-05-2007, 0701-2009 e 29-04-2009. As classificações MAXVER evidenciaram diversas alterações espaciais no uso do solo no período considerado. Os índices de vegetação mais adequados foram NDVI e SAVI - fator 0,25 , os quais apresentaram valores semelhantes de porcentagem de cobertura vegetal, mas discrepantes em relação ao valor inferido para a classificação MAXVER.

Palavras-chave: classificação de imagens; índices de vegetação; mapas de uso do solo.

\section{ABSTRACT}

This work aims to analyze the land use evolution in the city of Santa Cruz do Rio Pardo - SP through supervised classification of Landsat-5 TM satellite images according to the maximum likelihood (Maxlike), as well as verifying the mapping accuracy through Kappa index, comparing NDVI and SAVI vegetation indexes in different adjustment factors for the canopy substrate and determining the vegetal coverage percentage in all methods used on 2007, May $26^{\text {th. }} ; 2009$, January $7^{\text {th }}$ and 2009, April $29^{\text {th }}$. The Maxlike classification showed several spatial changes in land use over the study period. The most appropriated vegetation indexes were NDVI and SAVI - 0,25 factor, which showed similar values of vegetal coverage percentage, but discrepant from the inferred value for Maxlike classification.

Keywords: images classification; vegetation indexes; land use mapping.

\section{INTRODUÇÃO}

A emergência dos problemas ambientais na segunda metade do século XX impôs à humanidade a necessidade do desenvolvimento de metodologias e técnicas para a compreensão da dinâmica natural e ação sobre a natureza, de modo a mitigar e/ou recuperar os danos já causados pela ação humana. Entre estas metodologias, destaca-se o planejamento ambiental, voltado para o ordenamento e monitoramento do uso e ocupação do solo, seja através do gerenciamento de recursos hídricos e bacias hidrográficas, na delimitação das reservas legais, áreas de preservação permanente e proteção de áreas através dos parques e reservas, do monitoramento da cobertura vegetal, da atuação de 
pesquisadores, agrônomos, geógrafos e produtores rurais no planejamento da ocupação agrícola das terras e da produção do espaço urbano e rural, na adoção de medidas para a conservação do solo e práticas agrícolas sustentáveis, entre outras. Entre as técnicas e tecnologias disponíveis e crescentemente utilizadas, destacam-se o Sensoriamento Remoto e o Geoprocessamento.

Segundo Fonseca (2000), o uso de imagens de Sensoriamento Remoto como fonte de informação para a produção de mapas, é um dos grandes impulsionadores de inovações no ramo do Geoprocessamento. O grande interesse de seu uso advém da temporalidade da informação juntamente com seu relativo baixo custo, quando se busca informações de uso e cobertura do solo. Como a paisagem é mudada constantemente pela ação do homem, a interpretação de imagens de satélite é uma fonte indireta de se determinar a dinâmica dos processos econômicos e a expansão urbana, em ambiente de Geoprocessamento.

Uma metodologia bastante utilizada na elaboração de mapas de uso e ocupação do solo é a classificação digital de imagens de sensoriamento remoto. Segundo Crósta (1992, p.107),

A classificação automática de imagens multiespectrais de sensoriamento remoto diz respeito a associar cada pixel da imagem a um "rótulo" descrevendo um objeto real (vegetação, solo, etc.). Dessa forma, os valores numéricos (DNs) associados a cada pixel, definidos pela reflectância dos materiais que compõem esse pixel, são identificados em termos de um tipo de cobertura da superfície terrestre imageada (água, tipo de vegetação, de solo, de rocha, etc.), chamadas então de temas.

O método mais comum de classificação supervisionada de imagens, do tipo pixel-pixel, que utiliza a informação espectral isoladamente de cada "pixel" para achar regiões homogêneas, é o da máxima verossimilhança (MAXVER). O referido método considera a ponderação das distâncias entre as médias dos níveis digitais das classes cujas amostras de treinamento são definidas pelo 
usuário, utilizando parâmetros estatísticos e ajuste segundo uma distribuição gaussiana. Para que esta classificação seja precisa o suficiente, é necessário um número razoavelmente elevado de "pixels" para cada amostra de treinamento (INPE, 2009).

A acurácia das classificações temáticas pode ser avaliada através de vários métodos. Rosenfield e Fitzpatrick-Lins (1986) destacam, entre eles, a matriz de erros, que aponta, em sua diagonal principal, a proporção dos pixels classificados corretamente e, na soma dos valores marginais das linhas e colunas, respectivamente, os erros de inclusão e omissão para cada classe temática. Porém, o autor recomenda o uso do coeficiente Kappa, que utiliza todas as células da matriz de erro, e não apenas os elementos da diagonal, ou seja, mede a probabilidade de um pixel ser corretamente classificado em relação à probabilidade da classificação incorreta. Segundo Simões (2001), o coeficiente Kappa é calculado através da fórmula:

$$
K=P_{0}-P_{e} / 1-P_{e}
$$

Onde:

- $P_{0}$ representa a exatidão geral da classificação (soma da coluna diagonal da matriz dividida pelo número total de "pixels" amostrados);

- $\mathrm{Pe}=\Sigma \mathrm{p}_{\mathrm{i}+} \mathrm{p}_{+\mathrm{i}}$, sendo $\mathrm{p}_{\mathrm{i}_{+}}$e $\mathrm{p}_{+\mathrm{i}}$ as proporções marginais da linha $\mathrm{i}$ e da coluna i, respectivamente.

A exatidão dos mapeamentos calculada através do coeficiente Kappa pode ser determinada pela Tabela 1, desenvolvida por Landis e Koch (1977), que associa a um determinado intervalo de valores Kappa um grau de qualidade do mapa temático.

De acordo com Jensen (2009), as técnicas de sensoriamento remoto vêm sendo utilizadas desde a década de 1960 na modelagem de vários parâmetros biofísicos da vegetação, que podem ser medidos através dos 
índices de vegetação, denominados medidas radiométricas adimensionais que indicam a abundância relativa e a atividade da vegetação verde, incluindo índice de área foliar (IAF), porcentagem de cobertura verde, teor de clorofila, biomassa verde e radiação fotossinteticamente ativa absorvida (RFAA, ou APAR, em inglês). (JENSEN, 2009, p.384).

Tabela 1. Qualidade da classificação associada aos valores da estatística Kappa

\begin{tabular}{cc}
\hline Valor de Kappa & $\begin{array}{c}\text { Qualidade do } \\
\text { mapa temático }\end{array}$ \\
$0,000-0,20$ & Péssima \\
$0,20-0,40$ & Ruim \\
$0,40-0,60$ & Razoável \\
$0,60-0,80$ & Muito boa \\
$0,80-1,00$ & Excelente \\
\hline Fonte: Adaptada de Landis e Koch (1977, p.165)
\end{tabular}

Sendo assim, os índices de vegetação são também importantes indicadores da qualidade ambiental, além de serem bastante utilizados nos estudos sobre o meio ambiente.

Rosa (2009) afirma que os índices de vegetação utilizam as faixas do vermelho e do infravermelho próximo por conterem mais de $90 \%$ da variação da resposta espectral da vegetação e, portanto, tais índices realçam o seu comportamento espectral, correlacionando-os com os parâmetros biofísicos da mesma. De acordo com o autor, as faixas espectrais correspondentes ao 
vermelho $(0,65$ a $0,72 \mu \mathrm{m})$ e ao azul $(0,45$ a $0,50 \mu \mathrm{m})$ são as mais aproveitadas pela folha na fotossíntese, pois os pigmentos da planta responsáveis por ela absorvem a radiação incidente nos comprimentos de onda 0,48 $\mu \mathrm{m}$ (carotenóides) e 0,62 $\mu \mathrm{m}$ (clorofila). Dessa forma, a reflectância é muito baixa nestas faixas. Já na faixa do infravermelho próximo $(0,7$ a 1,3 $\mu \mathrm{m})$, segundo Moreira (2001), a absorção da radiação eletromagnética é muito baixa (menos de $15 \%$ ) e a reflectância pode chegar a $50 \%$ dependendo da estrutura anatômica das folhas. De acordo com Knipling (1970), a radiação solar sofre difusão e dispersão através da cutícula e da epiderme das células do mesófilo e das cavidades de ar no interior da folha. As múltiplas reflexões e refrações da radiação solar nestas estruturas devem-se à diferença entre o índice de refração do ar e o das paredes de celulose hidratadas, provavelmente em razão da superfície rugosa das microfibrilas das paredes celulares.

O índice de vegetação mais conhecido e utilizado é o Índice de Vegetação por Diferença Normalizada (NDVI - Normalized Difference Vegetation Index). Segundo Rouse et al. (1974) apud Gurgel (2000), o NDVI é expresso pela razão entre a diferença da medida da reflectância nos canais do infravermelho próximo e vermelho e a soma desses canais, ou seja:

$$
N D V I=(\rho N I R-\rho R e d) /(\rho N I R+\rho R e d)
$$

Onde: $\rho$ Red e $\rho N I R$ representam, respectivamente, os valores de reflectância na região do vermelho e infravermelho próximo do espectro eletromagnético de objetos na superfície terrestre.

Wang et al. (2005) afirmam que a correlação entre o NDVI e o Índice de Área Foliar (IAF) das plantas pode não ser tão forte durante os períodos de máximo IAF, aparentemente devido à saturação do NDVI nestas condições. $O$ intervalo dinâmico do índice NDVI é ampliado a favor de condições de baixa biomassa, mas comprimido a favor de condições de alta biomassa, de florestas. Elmore et al. (2000) afirmam que outra desvantagem do índice NDVI está no fato deste ser altamente influenciado pelo brilho e pelo efeito espectral do solo, o que prejudica as avaliações sobre a vegetação. Suas análises 
mostraram que a mesma mudança temporal na cobertura vegetal em solos com diferentes reflectâncias no infravermelho próximo, devido às diferenças de brilho, provocaram variações distintas no valor NDVI.

Para minimizar as influências do solo na caracterização do dossel das plantas, Huete (1988) desenvolveu o Índice de Vegetação Ajustado para o Solo (SAVI - Soil-Adjusted Vegetation Index), que pode ser expresso pela seguinte equação (EASTMAN, 2006):

$$
\text { SAVI }=[(\rho N I R-\rho R e d) /(\rho N I R+\rho R e d+L)] \cdot(1+L)
$$

Onde $\rho$ NIR é a reflectância na banda do infravermelho próximo, $\rho$ Red é a reflectância na banda do vermelho e $L$ é o fator de ajuste para o substrato do dossel. Para cobertura vegetal muito baixa, Huete (1988) sugere o fator $L$ de 1,0; para cobertura vegetal intermediária, fator 0,5, e para altas densidades de vegetação, fator 0,25. Quando o valor $L$ for igual a zero, o índice SAVI equivalerá ao índice NDVI.

Uma comparação entre o método da classificação supervisionada por máxima verossimilhança e o índice de vegetação NDVI para mapeamento das classes de uso do solo foi realizada por Pisani et al. (2009), na bacia do Rio das Pedras, município de Itatinga - SP, através de imagens CBERS-2B. Os resultados mostraram que o índice NDVI propiciou uma transição gradual entre os usos do solo e alguns indicativos de degradação ambiental, enquanto a classificação supervisionada por máxima verossimilhança, ao associar os pixels a determinadas classes, não foi sensível à transição gradual entre os mesmos, e identificou áreas menores que as verdadeiras na classe "solo exposto", em detrimento das áreas de pastagem, cuja área classificada foi superestimada. 


\section{OBJETIVOS}

Este trabalho teve como objetivo principal realizar uma análise temporal do uso do solo no município de Santa Cruz do Rio Pardo - SP pelo método da classificação supervisionada por máxima verossimilhança (MAXVER) de imagens do satélite Landsat- $5 \mathrm{TM}$, bem como comparar a configuração do uso do solo através dos índices de vegetação NDVI e SAVI - fatores de ajuste para o substrato do dossel 0,25, 0,5 e 1,0, em três períodos: 26-05-2007 (período seco), 07-01-2009 (período chuvoso) e 29-04-2009 (período seco).

Os objetivos específicos foram:

- Verificar a acurácia da classificação supervisionada MAXVER das imagens de satélite através do coeficiente Kappa;

- Detectar e analisar as possíveis alterações no uso do solo entre os períodos secos dos anos 2007 e 2009, e entre os períodos seco e chuvoso do ano de 2009;

- Determinar o índice de vegetação mais eficiente na detecção da cobertura vegetal e da ausência de vegetação nos períodos considerados;

- Determinar a porcentagem de cobertura do solo através do método da classificação supervisionada por máxima verossimilhança e dos índices de vegetação NDVI e SAVI.

\section{MATERIAIS E MÉTODOS}

\subsection{Materiais}

Os materiais utilizados no presente trabalho foram: 
- Imagens do satélite Landsat-5 Thematic Mapper, órbita/ponto 221/076, tomadas nos dias 26-05-2007, 07-01-2009 e 29-04-2009, bandas $3(0,63 \mu \mathrm{m}$ $0,69 \mu \mathrm{m}), 4(0,76 \mu \mathrm{m}-0,90 \mu \mathrm{m})$ e $5(1,55 \mu \mathrm{m}-1,75 \mu \mathrm{m})$;

- Cartas topográficas digitalizadas na escala 1:50.000 abrangendo o município de Santa Cruz do Rio Pardo, utilizadas na delimitação do limite do município, com as seguintes nomenclaturas: Domélia (folha SF-22-Z-B-IV-1), Ipauçu (folha SF-22-Z-C-III-2), Óleo (folha SF-22-Z-B-IV-3), Ourinhos (folha SF22-Z-A-VI-3), Santa Cruz do Rio Pardo (folha SF-22-Z-A-VI-4) e São Pedro do Turvo (folha SF-22-Z-A-VI-2) (IBGE, 1973);

- Software Idrisi 15.0 - The Andes Edition, sistema de informação geográfica desenvolvido pela Graduate School of Geography da Clark University, de Massachusets, Estados Unidos (EASTMAN, 2006), usado neste trabalho para realização da correção atmosférica, classificação supervisionada MAXVER, geração dos índices de vegetação NDVI e SAVI, cálculo de áreas e edição final dos mapas;

- Software Auto-Cad Map 2000, utilizado na vetorização do limite do município de Santa Cruz do Rio Pardo e conversão em formato que permitiu a importação no software Idrisi 15.0 - The Andes Edition.

\subsection{Caracterização da área de estudo}

O município de Santa Cruz do Rio Pardo localiza-se no Sudoeste do Estado de São Paulo, no Planalto Ocidental Paulista, em terrenos de rochas areníticas e basálticas (ROSS e MOROZ, 1997). Possui uma superfície de $1.116 \mathrm{~km}^{2}$ (IBGE, 2009), e situa-se entre as coordenadas 625135, 667560, 7455020 e 7509642 do fuso 22 Sul da projeção Universal Transversa de Mercator - UTM (IBGE, 1973). O ponto central da cidade apresenta latitude 2254' S, longitude 4937' W, e altitude média de 480 m, conforme Figura 1. 
O clima do município, de acordo com a classificação climática de Köeppen (MIRANDA et al., 2009), é Cwa (mesotérmico, com chuvas concentradas no verão e verões quentes). A temperatura média no mês mais quente é de $26^{\circ} \mathrm{C}$, com médias máximas de $32^{\circ} \mathrm{C}$. No mês mais frio, a temperatura média é de $18^{\circ} \mathrm{C}$, com média mínima de $12^{\circ} \mathrm{C}$. $\mathrm{O}$ índice pluviométrico médio anual é de 1.475,3 mm.

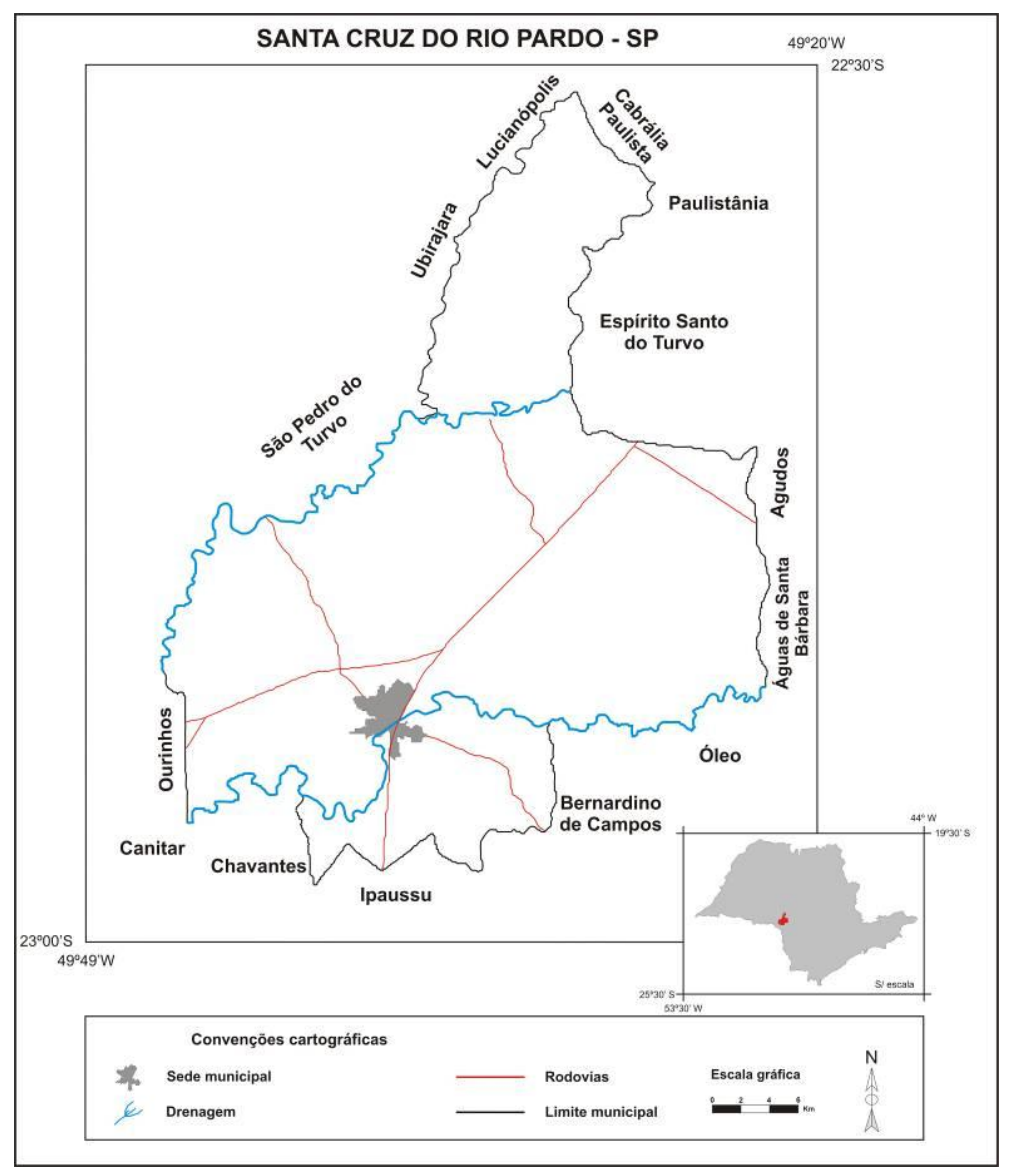

Figura 1. Localização do município de Santa Cruz do Rio Pardo - SP Organização: Demarchi (2009)

Em profunda interação com as características climáticas, a vegetação de Santa Cruz do Rio Pardo é classificada como Floresta Estacional Semidecidual Submontana (IBGE, 1992), conhecida por mata atlântica do interior e 
condicionada à dupla estacionalidade climática, na derivação "vegetação secundária e atividades agrárias" (IBGE, 2004).

De acordo com o Mapa Pedológico do Estado de São Paulo (OLIVEIRA, 1999), o município apresenta três tipos de solo: Latossolos Vermelhos (LV-1), Nitossolos Vermelhos (NV-1) e Argissolos Vermelho-Amarelos (PVA-2). É banhado pelo Rio Pardo, em sua porção Sul, e pelo Rio Turvo, na porção Norte e Oeste, ambos afluentes do Rio Paranapanema, além de inúmeros córregos, e faz parte da Unidade de Gerenciamento de Recursos Hídricos do Médio Paranapanema - UGRHI-17 (SÃO PAULO, 1996).

\subsection{Métodos}

Para atingir os objetivos propostos, foram adotados os seguintes procedimentos metodológicos:

- Aquisição das imagens Landsat-5, órbita/ponto 221/076, tomadas nos dias 26-05-2007, 07-01-2009 e 29-04-2009, através da página do Instituto Nacional de Pesquisas Espaciais - http://www.inpe.br;

- Vetorização do limite do município de Santa Cruz do Rio Pardo - SP sobre as cartas topográficas digitalizadas no software Auto-Cad Map 2000 (datum horizontal Córrego Alegre), conversão no formato $d x f$ e importação pelo software Idrisi 15.0 - The Andes Edition, com posterior mudança do datum para SAD-69 através do módulo Convert;

- Importação das imagens Landsat-5 georreferenciadas em formato geotiff no software Idrisi Andes (datum horizontal: SAD-69), nas bandas 3, 4 e 5 , com posterior correção do georreferenciamento através do módulo Resample, tendo como parâmetro os cursos d'água que coincidem com o limite do município, de modo a permitir a sobreposição correta deste sobre a imagem; 
- Correção atmosférica das imagens Landsat-5, através dos parâmetros estabelecidos nos seus arquivos de parâmetros, efetuada por meio do módulo Atmosc do Idrisi Andes, de forma a minimizar os efeitos atmosféricos sobre as mesmas e dispor os níveis de cinza entre os valores 0 e 1 , possibilitando a geração do índice SAVI;

- Recorte das bandas corrigidas e sem correção atmosférica, com limites próximos aos limites máximos e mínimos de latitude e longitude do município, através do módulo Window do Idrisi Andes. Todas as bandas e imagens foram recortadas com os mesmos limites;

- Geração dos índices de vegetação NDVI e SAVI - fatores de ajuste para substrato do dossel 0,25, 0,5 e 1,0 para todas as imagens de satélite, por meio do módulo Vegindex do Idrisi Andes, com posterior fatiamento das imagens NDVI e SAVI em classes de intervalo 0,1 para as classes mais representativas, e de intervalo maior para as classes menos representativas, através do módulo Reclass, seguido da edição final e cálculo das áreas das classes dos índices de vegetação através do módulo Area;

- Análise dos histogramas das imagens NDVI e SAVI antes do fatiamento e do recorte dos limites do município de Santa Cruz do Rio Pardo, dando ênfase aos parâmetros média, desvio padrão e valores mínimo e máximo de NDVI e SAVI;

- Geração dos histogramas das bandas 3, 4 e 5, aplicação do contraste através do módulo Stretch e elaboração de composições coloridas falsa-cor 543 das imagens Landsat-5 TM;

- Coleta de amostras de treinamento vetoriais das diferentes classes de uso do solo nas composições 543, com atribuição de um indicador para cada variação do mesmo tipo de uso do solo e para as classes diferentes, criação da assinatura espectral dos usos do solo (módulo Makesig) e realização da classificação supervisionada pelo método MAXVER (máxima verossimilhança), através do módulo Maxlike; 
- Agrupamento dos usos do solo de mesma classe, porém com assinaturas espectrais diferentes, pelo processo de reclassificação (módulo Reclass). As classes de uso do solo definitivas são: 1. Solo exposto; 2. Açudes; 3. Cana-de-açúcar; 4. Mata nativa; 5. Eucalipto; 6. Laranja; 7. Pastagem; 8. Culturas anuais (soja, milho, aveia etc.); 9. Zona urbana; 10. Nuvens (apenas na imagem de 29-04-2009);

- Aplicação do filtro de moda $3 \times 3$ (módulo Filter) nas imagens reclassificadas, objetivando atenuar o efeito dos ruídos existentes nas imagens devido aos erros na transmissão do sinal e às diferenças de sensibilidade dos detectores (NOVO, 1992), além de corrigir pequenos erros de classificação;

- Vetorização em tela da zona urbana e rasterização sobre a imagem classificada;

- Edição final dos mapas com a criação das legendas, paletas de cores, escala, Norte e informações gerais, e cálculo da área de cada classe de uso do solo no módulo Area do Idrisi Andes;

- Cálculo do coeficiente Kappa, que avalia a exatidão geral e por categoria do mapeamento. Para sua determinação, foi criado um arquivo vetorial de pontos de amostragem através do módulo Sample, que foi sobreposto sobre a respectiva composição colorida falsa-cor 543 , não recortada, para anotação do indicador da classe correta de uso do solo em um arquivo de formato avl. Em seguida, através do módulo Assign, os indicadores corretos de uso do solo foram associados ao arquivo vetorial de pontos de amostragem, para finalmente gerar o coeficiente Kappa, cruzando-se $o$ arquivo gerado no módulo Assign com a imagem classificada. Foram elaborados dois coeficientes diferentes para cada imagem considerada: o Random, com pontos de amostragem aleatoriamente distribuídos, e o Systematic, cujos pontos de amostragem formam uma grade regular;

- Após a elaboração dos cartogramas, procedeu-se à discussão conjunta dos resultados obtidos. 


\section{RESULTADOS E DISCUSSÃO}

As Figuras 2 a 4 e as Tabelas 2 a 4 mostram as classes de uso do solo do município de Santa Cruz do Rio Pardo - SP, bem como a área ocupada por cada classe, obtidas a partir da classificação supervisionada por máxima verossimilhança das imagens Landsat-5 TM, nas datas 26-05-2007, 07-012009 e 29-04-2009.

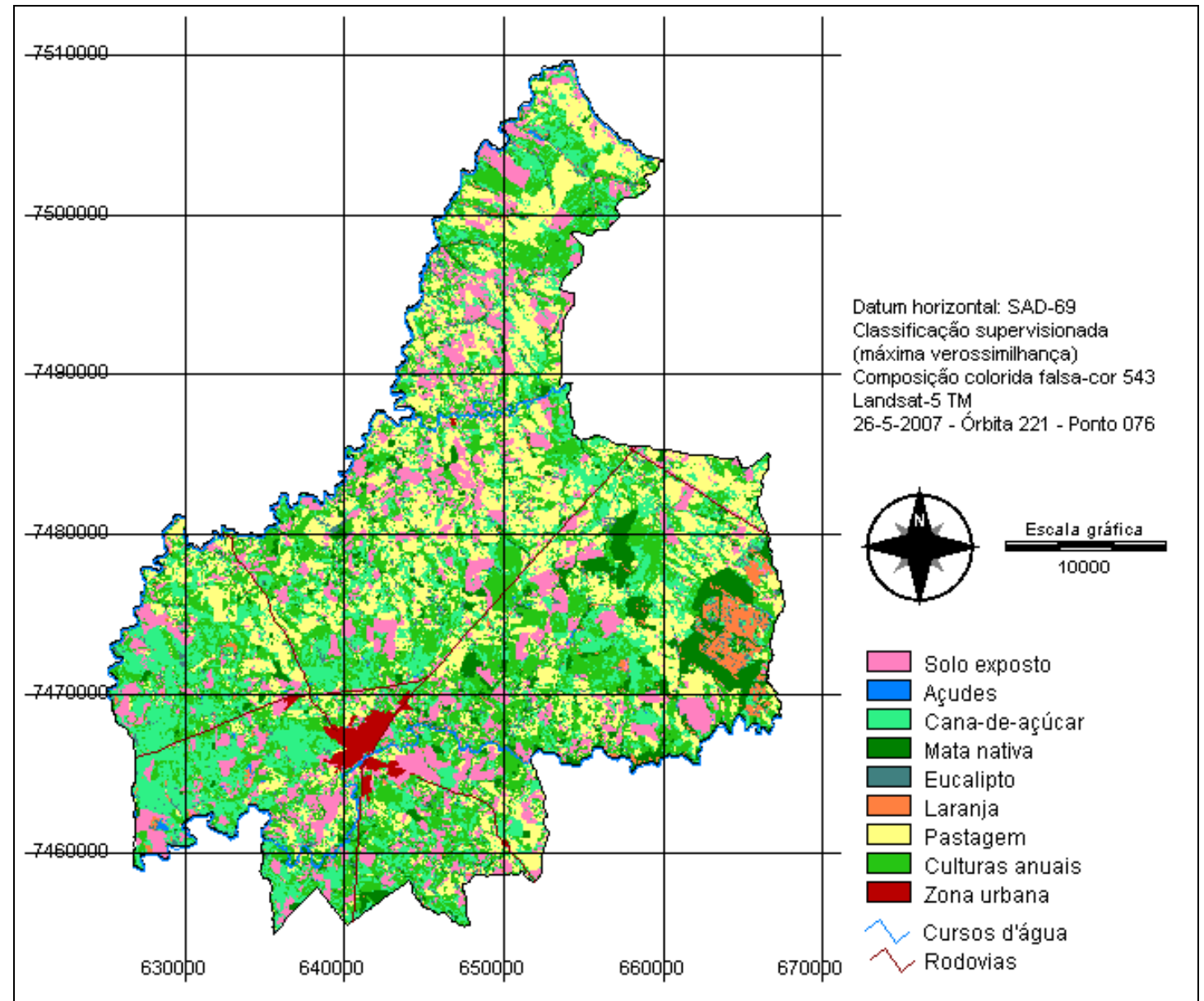

Figura 2. Santa Cruz do Rio Pardo - SP: uso do solo em 26-05-2007 Elaboração: Demarchi (2009) 
Tabela 2. Santa Cruz do Rio Pardo: área das classes de uso do solo em 26-05-2007.

\begin{tabular}{l|c|c}
\hline Classes & Área $\left.\mathbf{( k m}^{2}\right)$ & $\%$ \\
\hline Solo exposto & 164,529 & 14,7 \\
Açudes & 3,1563 & 0,3 \\
Cana-de-açúcar & 249,5862 & 22,3 \\
Mata nativa & 76,563 & 6,9 \\
Eucalipto & 30,7359 & 2,8 \\
Laranja & 24,7806 & 2,2 \\
Pastagem & 262,1934 & 23,5 \\
Culturas anuais & 293,8383 & 26,3 \\
Zona urbana & 12,0672 & 1,1 \\
\hline Total & $1.117,4499$ & 100,0 \\
\hline
\end{tabular}

Elaboração: Demarchi (2009) 
RA'E GA 21 (2011), p. 234-271

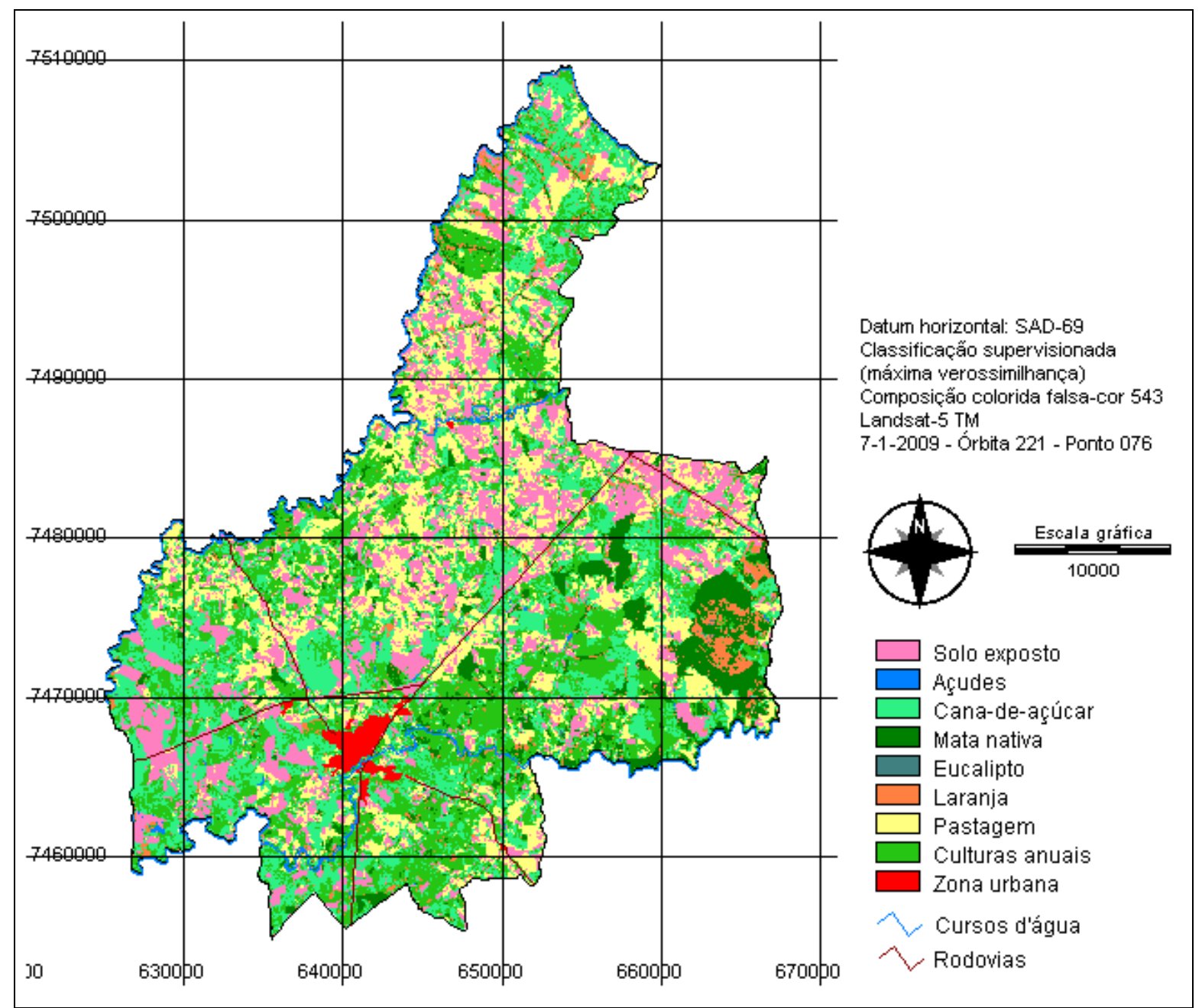

Figura 3. Santa Cruz do Rio Pardo - SP: uso do solo em 07-01-2009 Elaboração: Demarchi (2009) 
Tabela 3. Santa Cruz do Rio Pardo: área das classes de uso do solo em 07-012009

\begin{tabular}{l|c|c}
\hline Classes & Área $\left.\mathbf{( k m}^{\mathbf{2}}\right)$ & $\%$ \\
\hline Solo exposto & 201,222 & 18,0 \\
Açudes & 5,6268 & 0,5 \\
Cana-de-açúcar & 263,6055 & 23,6 \\
Mata nativa & 78,372 & 7,0 \\
Eucalipto & 1,4193 & 0,1 \\
Laranja & 44,0802 & 3,9 \\
Pastagem & 223,7391 & $\mathbf{1 0 0 , 0}$ \\
\hline Culturas anuais & $\mathbf{1 . 1 1 7 , 4 1 1 2}$ & 20,0 \\
\hline Zona urbana & 12,0492 & 1,1 \\
\hline
\end{tabular}

Elaboração: Demarchi (2009) 


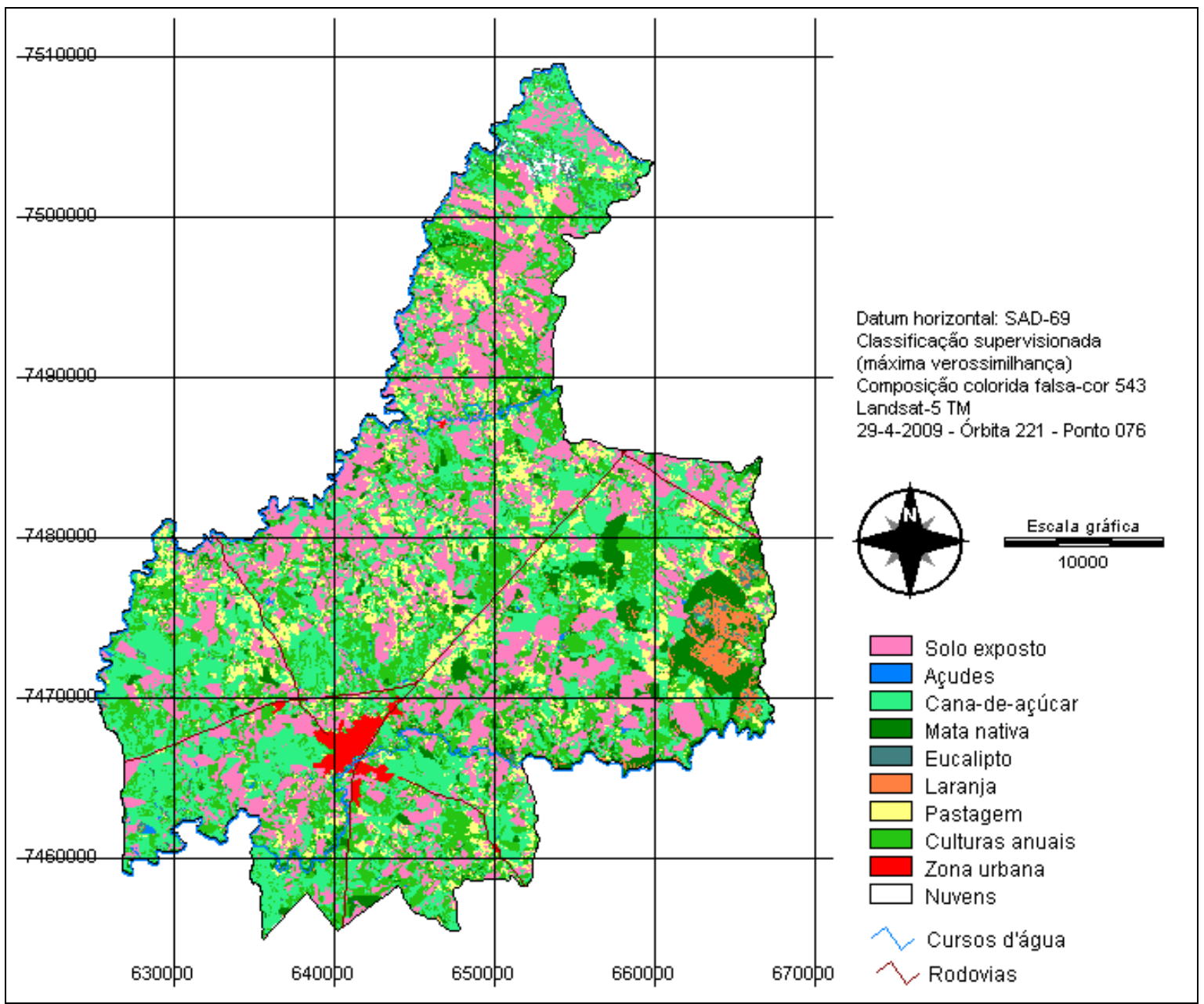

Figura 4. Santa Cruz do Rio Pardo - SP: uso do solo em 29-04-2009 Elaboração: Demarchi (2009) 
Tabela 4. Santa Cruz do Rio Pardo: área das classes de uso do solo em 29-042009

\begin{tabular}{l|c|c}
\hline Classes & Área $\mathbf{( \mathbf { k m } ^ { 2 } )}$ & $\%$ \\
\hline Solo exposto & 288,7299 & 25,8 \\
Açudes & 4,7025 & 0,4 \\
Cana-de-açúcar & 324,3582 & 29,0 \\
Mata nativa & 70,3089 & 6,3 \\
Eucalipto & 14,931 & 1,3 \\
Laranja & 19,7163 & 1,8 \\
Pastagem & 110,043 & 9,8 \\
Culturas anuais & 270,0432 & 24,2 \\
Zona urbana & 12,0438 & 1,1 \\
\hline Nuvens & 2,5335 & $\mathbf{1 0 0 , 0}$ \\
\hline Total & $\mathbf{1 . 1 1 7 , 4 1 0 3}$ & 0,2 \\
\hline
\end{tabular}

Elaboração: Demarchi (2009)

A análise comparativa temporal entre as classes de uso do solo no período seco (outono) nas datas 26-05-2007 e 29-04-2009 permite constatar algumas alterações em sua configuração. Do período considerado entre $2007 \mathrm{e}$ 2009, houve um aumento significativo na área de solo exposto (de 14,7\% para 25,8 \%) e uma redução considerável nas áreas destinadas à pastagem (de 23,5 \% para 9,8 \%). Ademais, ocorreu o aumento da área cultivada com canade-açúcar, de 22,3 \% para 29,0 \%, e variação muito pequena na área cultivada 
com culturas anuais $(26,3 \%$ a $24,2 \%)$. É importante destacar que a configuração de solo exposto é geralmente transitória, ocorrendo nos períodos de entressafra, de preparo do solo para o plantio de culturas anuais e de rebrota da cana-de-açúcar. Além disso, diversas culturas são colhidas entre os meses de abril e maio, justificando as alterações nas áreas de solo exposto entre os mapas em questão. Vale ressaltar, ainda, que a cana-de-açúcar, cultivada em grandes propriedades e ocupando grandes áreas, é colhida geralmente entre os meses de abril e dezembro, sendo o calendário de corte variável, pois é definido pelas usinas de açúcar e álcool que dela se beneficiam.

A análise das figuras mostra, porém, que as regiões com predomínio de solo exposto em 29-04-2009 (Norte, Noroeste e Nordeste), eram predominantemente ocupadas por pastagem em 26-05-2007. Na porção Oeste, o solo exposto substituiu os cultivos de cana-de-açúcar e outras culturas anuais, provavelmente já colhidas na data de obtenção da imagem de satélite, e na porção Sul, a pastagem foi substituída pelos cultivos de cana-de-açúcar e algumas culturas anuais.

Visualizada individualmente, a área ocupada pelos pomares de laranja em sua principal região de ocorrência (Leste do município) não sofreu variação significativa. No entanto, diversas áreas ao redor dos cursos d'água, ocupadas por mata ciliar, cujas amostras de treinamento foram associadas à classe "mata nativa", foram classificados erroneamente como cultivo de laranja devido à semelhança na resposta espectral entre o dossel formado pelos pomares e a mata ciliar. A cultura do eucalipto, que ocupa uma porção muito pequena do município, não foi adequadamente identificada em nenhum dos períodos considerados, apresentando confusão com as áreas de mata ciliar e cultivadas com laranja. Como a área ocupada é pequena, o número de amostras de treinamento coletadas nas classificações foi insuficiente para caracterizar sua assinatura espectral. 
Em relação à exatidão da classificação das imagens, os coeficientes Kappa determinados para as classificações de 26-05-2007 e 29-04-2009 mostraram os seguintes resultados: para a classificação de 26-05-2007, o coeficiente Kappa Random (pontos de amostragem aleatoriamente distribuídos) foi de 0,6132 , qualidade "muito boa" segundo valores definidos na Tabela 1, e o coeficiente Kappa Systematic (pontos de amostragem regularmente distribuídos) foi de 0,47 , classificação considerada "boa". Deve-se ressaltar que os procedimentos utilizados no cálculo da exatidão dos mapeamentos para os esquemas de amostragem Random e Systematic são semelhantes, sendo a única diferença a distribuição dos pontos de amostragem, mas apresentaram resultados discrepantes. A resolução espacial da imagem utilizada foi um fator limitante no mapeamento, pois mesclou as transições entre os usos do solo em apenas um nível de cinza do pixel (30 × 30 metros), o que influenciou negativamente a determinação do índice Kappa.

O coeficiente Kappa da imagem classificada de 29-04-2009 apresentou, no esquema de amostragem Random, o valor 0,6142, e no esquema de amostragem Systematic, o valor 0,6054, resultados bem próximos, que evidencia uma melhor qualidade do mapeamento, embora próximo ao limite entre a classificação considerada "boa" e "muito boa". Os valores Kappa da imagem classificada de 07-01-2009 são discrepantes entre si, porém, relativamente mais elevados, o que atesta uma melhor amostragem na realização da classificação supervisionada: o esquema de amostragem Random apresentou o coeficiente de 0,5714 , e o esquema Systematic, o coeficiente 0,7415 .

Comparando as áreas das classes de uso do solo e sua distribuição espacial entre as imagens obtidas em períodos diferentes do mesmo ano (0701-2009 e 29-04-2009), constata-se que as principais modificações ocorreram nas classes solo exposto e pastagem, havendo o aumento das áreas de solo exposto (de $18 \%$ para 25,8\%), e a redução das áreas de pastagem (de $20 \%$ para $9,8 \%$ ). O aumento das terras com solo exposto decorre da colheita de parte das culturas anuais de verão, que geralmente ocorre nos primeiros 
meses do ano, sobretudo a soja. A área ocupada pelas culturas anuais reduziu, do período chuvoso (07-01-2009) para o período seco (29-04-2009), de 287,297 para $270,043 \mathrm{~km}^{2}$. As áreas ocupadas por soja no início da floração em 07-01-2009, de aspecto verde amarelado, foram substituídas por solo exposto em 29-04-2009, devido à sua colheita. A redução da área ocupada por pastagem ocorreu, sobretudo, nas porções Norte, Nordeste e Noroeste do município. Já na porção Sudeste, as culturas anuais foram colhidas e substituídas pelo solo exposto. A variação na área ocupada por cana-deaçúcar, de 23,6 \% para $29 \%$ entre os períodos chuvoso e seco, deve-se ao calendário de corte das extensas áreas cultivadas, de modo a abastecer as usinas de açúcar e álcool. Mesmo assim, apresentou crescimento em todo o período do mapeamento. A área ocupada pela mata nativa apresentou uma variação muito pequena em todo o período considerado, e foi bem individualizada em relação às outras classes. Porém, as matas ciliares de menor porte (capoeiras e capoeirões) não foram enquadradas corretamente na classe "mata nativa".

Considerando as classes de uso do solo cana-de-açúcar, mata nativa, reflorestamento, laranja, pastagem e culturas anuais para estimar a porcentagem de cobertura vegetal dos mapas em questão, obtiveram-se os seguintes resultados: em 26-05-2007, o município de Santa Cruz do Rio Pardo possuía 83,91\% de cobertura vegetal; em 07-01-2009, a cobertura vegetal estimada foi de $80,41 \%$ e, em 29-04-2009, de 72,43\%. Com base nestes dados, constata-se uma redução da cobertura vegetal do município entre os anos 2007 e 2009. As principais razões para esta redução são: diminuição das áreas ocupadas por pastagem, e aumento das áreas de solo exposto.

A Figura 5 mostra os índices de vegetação expressos em classes NDVI (Índice de Vegetação por Diferença Normalizada) e SAVI (Índice de Vegetação Ajustado ao Solo), este último com fatores de ajuste para o substrato do dossel 0,25, 0,5 e 1,0, do município de Santa Cruz do Rio Pardo - SP em 26-05-2007. 


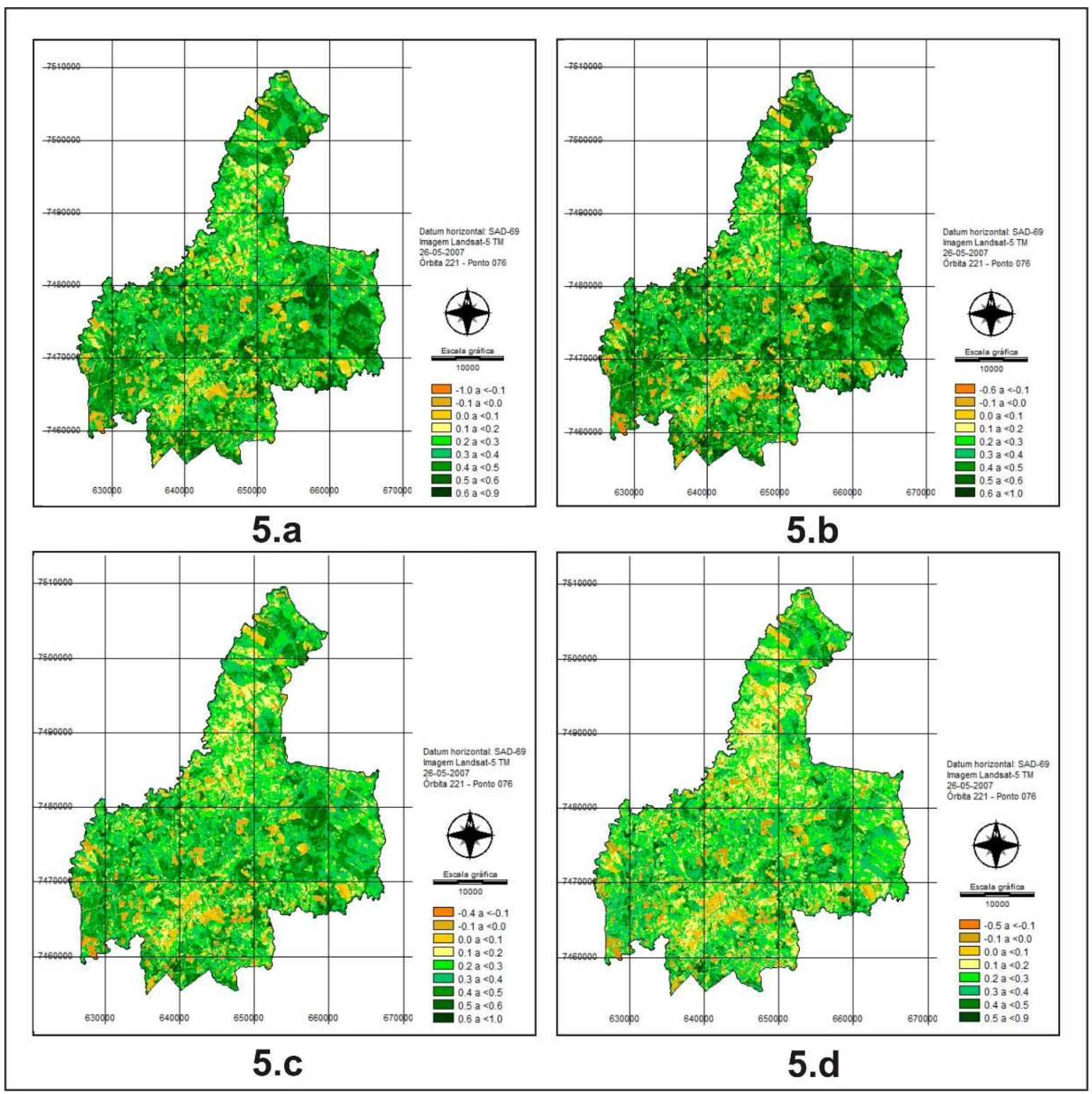

Figura 5. Santa Cruz do Rio Pardo: 5.a. Imagem NDVI; 5.b. Imagem SAVI fator de ajuste para o substrato do dossel 0,25; 5.c. Imagem SAVI - fator de ajuste para o substrato do dossel 0,$5 ; 5 . d$. Imagem SAVI - fator de ajuste para o substrato do dossel 1,0, em 26-05-2007 Elaboração: Demarchi (2009)

O Índice de Vegetação por Diferença Normalizada (NDVI) do dia 26-052007 apresentou as seguintes características: a classe de intervalo $-1,0$ a $<-0,1$ representou apenas 0,2291\% da área total do município, e coincidiu com parte dos açudes, enquanto as áreas de solo exposto concentraram-se entre as classes de NDVI-0,1 a <0,2. As áreas de pastagem, cana-de-açúcar e culturas anuais recém-cultivadas, ou seja, cobertura "rala" do solo, concentraram-se nas classes de NDVI 0,2 a <0,4, que representam, juntas, 42,425\% da área do 
município. A classe de NDVI 0,4 a $<0,5$ agrupou as áreas de cultivo de canade-açúcar, laranja e algumas culturas anuais de alta densidade de cobertura vegetal. A classe de NDVI 0,5 a $<0,6$ agrupou as matas nativas, parte das culturas anuais e pequena parcela de cana-de-açúcar de elevado vigor vegetativo, enquanto a classe de 0,6 a $<0,9$ reuniu outras áreas de mata nativa de elevada cobertura vegetal, totalizando apenas $1,781 \%$ da área total do município.

Embora a imagem NDVI em questão seja eficiente na distinção das classes de solo com cobertura vegetal e solo exposto, não faz uma distinção correta entre os diversos tipos de vegetação, ocorrendo o mesmo tipo em classes de NDVI diferentes, porém próximas. $O$ índice em questão foi eficiente para medir o vigor vegetativo, mas a quase totalidade da área do município ficou concentrada entre os valores $-0,1$ e 0,7 , o que contribuiu para homogeneizar determinados tipos de vegetação com diferentes respostas espectrais.

O Índice de Vegetação Ajustado ao Solo (SAVI) de 26-05-2007 com fator de ajuste para o substrato do dossel 0,25, comumente utilizado para áreas de vegetação densa onde a influência do fator solo na refletância dos alvos é reduzida, concentra as classes de ocorrência de solo exposto entre -0,2 e 0,2, diferenciando-o conforme a intensidade da reflexão da luz solar: solos que apresentaram aspecto roxo na composição colorida falsa-cor 543 tiveram valores SAVI entre - 0,2 e - $-0,1$, enquanto solos de aspecto rosa claro e médio apresentaram valores SAVI entre 0 e 0,2. O intervalo entre -0,2 e 0,2 representa $19,067 \%$ da área do município. Já os valores SAVI do solo vegetado apresentaram comportamento semelhante ao índice NDVI, ou seja, nas classes de 0,2 a <0,7, homogeneizando determinados usos do solo de assinatura espectral distinta. Houve uma menor porcentagem de pixels classificados no intervalo de 0,2 a $<0,5$ em relação à imagem NDVI, e uma maior porcentagem dos pixels classificados entre 0,5 e 0,7 , aumentando, portanto, as classes de maior vigor vegetativo. 
O índice SAVI da mesma data com fator de ajuste para o substrato do dossel 0,5, com aplicação recomendada para regiões de cobertura vegetal de densidade média, apresentou alguns resultados semelhantes e outros distintos dos índices discutidos anteriormente: os valores SAVI para solo exposto situaram-se entre -0,2 e 0,2. As áreas que apresentaram aspecto roxo escuro e rosa escuro na composição falsa-cor 543 tiveram valores SAVI menores, e os solos de aspecto mais claro, valores maiores. A área correspondente a este intervalo representa $24,11 \%$ da área total do município. Já os solos com cobertura vegetal escassa, ocupados por pastagem, laranja ou recémcultivados, apresentaram valor SAVI entre 0,2 e 0,3, e sua superfície ocupa cerca de $22,29 \%$ da área do município. As áreas vegetadas ficaram concentradas em um intervalo menor de valores SAVI: 0,3 a $<0,6$, o que representa 53,10\% da área do município, e agrupam, no intervalo de 0,3 a $<0,4$, culturas anuais, laranja, cana-de-açúcar e pastagem; no intervalo de 0,4 a $<0,5$, cana-de-açúcar, culturas anuais e mata nativa, no intervalo 0,5 a <0,6, mata nativa e cana-de-açúcar de maior densidade de cobertura vegetal. Tal resultado mostra uma redução da sensibilidade do fator de ajuste 0,5 para quantificar e diferenciar a vegetação quanto à densidade de cobertura e parâmetros biofísicos.

O índice SAVI de 26-05-2007 com fator de ajuste para o substrato do dossel 1,0, recomendado para áreas de densidade vegetal baixa, detectou os seguintes resultados: as classes SAVI inferiores a $-0,1$ representam apenas $0,35 \%$ da área total de Santa Cruz do Rio Pardo, e as classes superiores a $<0,6$, apenas $0,07 \%$ desta área. $O$ solo exposto ficou restrito às classes de valores entre - 0,1 e 0,2, embora a classe de 0,1 a $<0,2$ tenha agrupado os usos solo exposto e "cobertura rala" do terreno por pastagem ou cultivo recente de culturas anuais e cana-de-açúcar. O intervalo - 0,1 a $<0,2$ representou 31,69\% da área do município. A vegetação arbórea e as culturas agrícolas de cobertura vegetal densa ficaram restritas às classes de SAVI 0,2 a <0,6: a classe 0,2 a $<0,3$ agrupou, porém, os valores de cobertura vegetal escassa, cultivo de laranja, cana-de-açúcar e diversas culturas anuais; o intervalo 0,3 a $<0,5$ reuniu principalmente as classes mata nativa e cana-de-açúcar, sendo o valor NDVI 
diretamente proporcional à densidade de cobertura vegetal; e o intervalo superior mapeou apenas as matas nativas mais densas, representando 1,22\% da área do município.

A Tabela 5 mostra os valores de média, desvio padrão e valores mínimo e máximo dos índices de vegetação em questão, para as imagens NDVI e SAVI antes do fatiamento em classes e do recorte do limite do município.

Tabela 5. Média, desvio padrão e valores máximo e mínimo dos índices NDVI e SAVI do município de Santa Cruz do Rio Pardo - SP em 26-05-2007

\begin{tabular}{c|cccc}
\hline Índices & \multicolumn{1}{c}{ Média } & \multicolumn{1}{c}{$\begin{array}{l}\text { Desvio } \\
\text { padrão }\end{array}$} & Mínimo & Máximo \\
\hline NDVI & 0,348 & 0,157 & -1 & 1 \\
SAVI-0,25 & 0,353 & 0,176 & $-0,561$ & 0,932 \\
SAVI-0,5 & 0,301 & 0,151 & $-0,464$ & 0,907 \\
SAVI-1,0 & 0,255 & 0,13 & $-0,405$ & 0,877 \\
\hline
\end{tabular}

Elaboração: Demarchi (2009)

A análise da Tabela mostra que o índice SAVI - 0,25 apresentou o maior desvio padrão, o que denota uma maior variabilidade e contraste entre as diferentes classes de uso do solo, seguido do índice NDVI, que possui o segundo maior desvio padrão e valores que variam entre os limites mínimo e máximo de NDVI $(-1,0$ e 1,0). Considerando a cobertura vegetal relativamente densa do município e a maior capacidade de distinguir os diferentes usos do solo e cobertura vegetal, observa-se que o índice SAVI - fator de ajuste para o substrato do dossel 0,25 é o índice de vegetação mais adequado para representar as diferenças de vegetação na imagem de satélite em questão, seguido do índice NDVI, cujos resultados foram parecidos. 
A Figura 6 mostra os valores NDVI e SAVI - fatores de ajuste do substrato do dossel 0,25, 0,5 e 1,0 do município de Santa Cruz do Rio Pardo SP para o dia 07-01-2009.

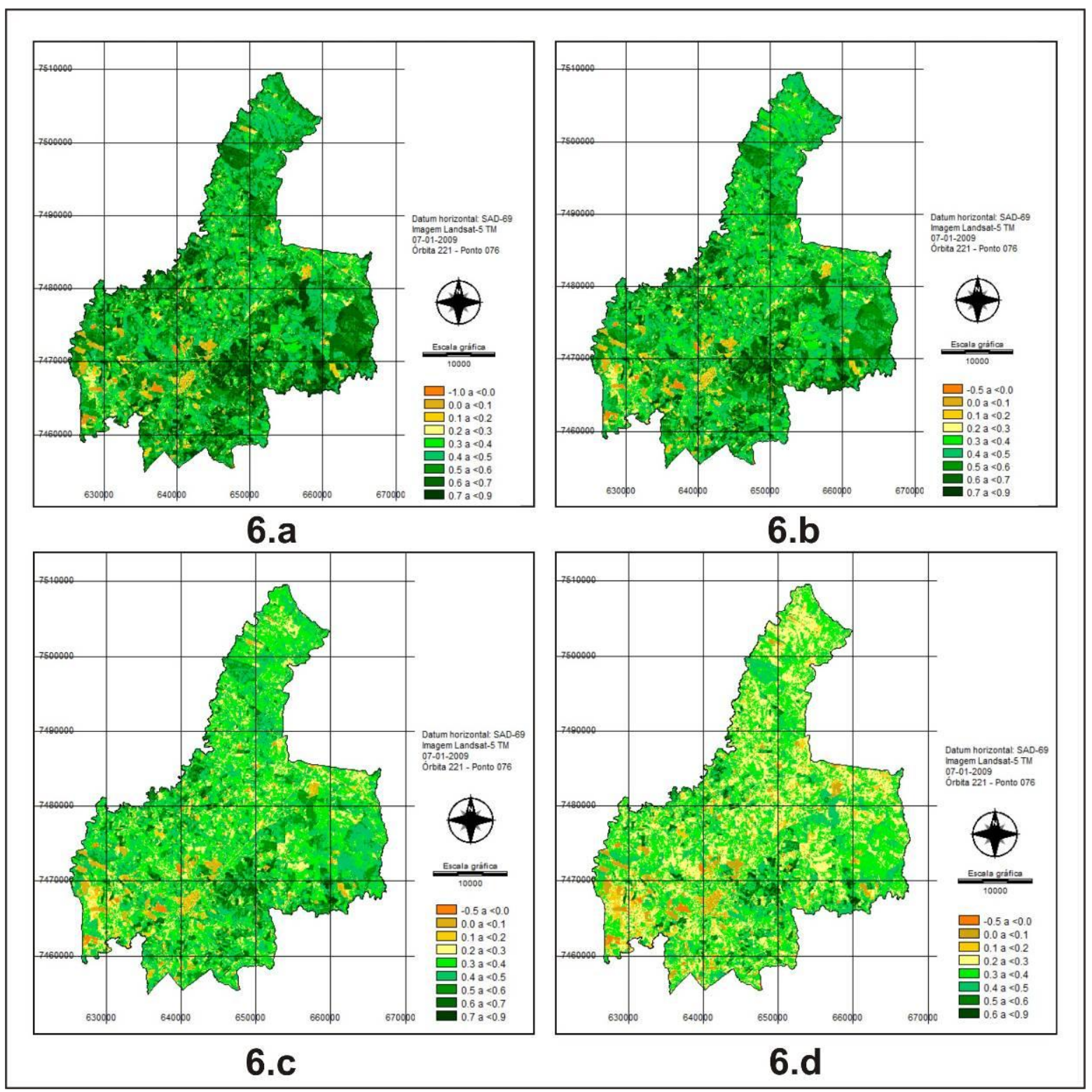

Figura 6. Santa Cruz do Rio Pardo: 6.a. Imagem NDVI; 6.b. Imagem SAVI fator de ajuste para o substrato do dossel 0,$25 ; 6$.c. Imagem SAVI - fator de ajuste para o substrato do dossel 0,$5 ; 6$.d. Imagem SAVI - fator de ajuste para o substrato do dossel 1,0, em 07-01-2009 Elaboração: Demarchi (2009)

Analisando a imagem NDVI do dia 07-01-2009, é possível chegar às seguintes constatações: apenas $0,67 \%$ da área total do município apresentou valores negativos de NDVI, demonstrando que mesmo as classes de solo 
exposto, que indicam ausência de vegetação, apresentaram valor de NDVI positivo. A classe solo exposto enquadrou-se no intervalo de $-0,1$ a $<0,4$, com área total representando $23,60 \%$ do município, assim distribuídos: o intervalo de $-0,1$ a $<0$ reuniu os solos de aspecto roxo escuro na composição 543 do Landsat-5 TM, resultado do corte recente da cana-de-açúcar, que ainda conserva matéria orgânica e umidade superficial no solo; o intervalo de 0 a $<0,1$, reuniu os solos de aspecto rosa e lilás, característicos de áreas cuja cobertura vegetal foi retirada há um certo tempo; o intervalo 0,1 a $<0,2$, os solos de aspecto roxo médio, que representam as áreas onde a cobertura vegetal foi retirada em um tempo intermediário entre as duas classes anteriores; o intervalo 0,2 a $<0,3$, os solos expostos com indícios de início de rebrota da cana-de-açúcar, e o intervalo de 0,3 a $<0,4$ reuniu solos ocupados por pastagem, solos com baixa intensidade de cobertura e recém plantados com culturas anuais e cana-de-açúcar. A classe de intervalo 0,4 a $<0,5$ agrupou vários usos do solo: cana-de-açúcar, pastagem e algumas culturas anuais, com área total representando $28,23 \%$ do município, a exemplo do intervalo de 0,5 a $<0,6$, que reuniu principalmente cultivo de cana-de-açúcar, parte dos pomares de laranja e algumas culturas anuais e ocupou $24,48 \%$ do território do município. As classes seguintes reuniram os usos do solo de maior cobertura e vigor da vegetação: entre 0,6 e <0,7, destacaram-se a mata nativa, parte dos pomares de laranja e das culturas anuais, e o intervalo superior reuniu as matas nativas de maior densidade de cobertura vegetal e as lavouras de soja no início da floração, que também apresentam elevada cobertura do solo.

A cana-de-açúcar, por apresentar diferentes estágios de desenvolvimento no município, apresentou respostas espectrais bastante dispersas, e foi classificada em intervalo grande de valores NDVI. Os demais usos do solo também foram diferenciados de acordo com suas respostas espectrais, sendo razoavelmente distribuídos nas classes do referido índice.

A imagem do índice SAVI - fator de ajuste para o substrato do dossel 0,25 , recomendado para solos com cobertura vegetal densa, apresentou 
distribuição de valores próxima à imagem NDVI, porém, com área relativamente maior nas classes $0,3 a<0,5$, que reuniu culturas anuais recémcultivadas, cana-de-açúcar e pastagem, e área menor nos intervalos 0,5 a $<0,6$, que reuniu as culturas laranja, cana-de-açúcar e mata nativa; 0,6 a $<0,7$, que agrupou mata nativa e cana-de-açúcar; e 0,7 a $<0,9$, basicamente detectando as lavouras de soja no início da floração, que apresentam elevado vigor e cobertura vegetal, sobretudo no intervalo situado entre 0,7 e $<0,8$. A zona urbana do município e as rodovias, devido à superfície heterogênea, apresentaram valor SAVI entre 0 e 0,3.

A imagem SAVI com fator de ajuste para o substrato do dossel 0,5 , recomendado para áreas de cobertura vegetal média, apresentou as seguintes características: concentração dos valores entre $-0,1$ e 0,8 , a exemplo dos índices anteriores. Porém, $77,04 \%$ da área do município concentraram-se no intervalo de 0,2 a 0,5, sendo que a classe 0,3 a $<0,4$ representa $35,31 \%$ da sua área total, reunindo os usos do solo cana-de-açúcar, mata nativa, culturas anuais, pastagem e laranja. As classes de menores e maiores valores $(-0,5 \mathrm{a}$ $<0,2$ e 0,5 a $<0,9$, respectivamente) representam os mesmos usos do solo dos índices anteriores: solo exposto e pastagem, para o intervalo mais baixo, e mata nativa e cana-de-açúcar para os valores SAVI mais elevados, porém, sua área total é menor em relação aos índices NDVI e SAVI - fator 0,25.

Finalmente, a imagem SAVI - fator de ajuste para o substrato do dossel 1,0 , utilizado em regiões de baixa cobertura vegetal, concentra os valores SAVI entre -0,1 e 0,7, e acentua a tendência observada no índice SAVI - fator 0,5. As classes de valores 0,2 a $<0,5$ representam $84,29 \%$ da área do município, e a classe de intervalo 0,3 a $<0,4$ concentra $38,38 \%$ da sua área total, reunindo os usos cana-de-açúcar, mata nativa, laranja, pastagem e culturas anuais, enquanto a classe 0,2 a $<0,3$ reúne os usos pastagem, culturas anuais recémcultivadas, solo exposto e cana-de-açúcar, perfazendo $29,85 \%$ da área total do município. 
É importante destacar que a imagem foi obtida no mês de janeiro, um período chuvoso, o qual propicia, teoricamente, uma maior cobertura vegetal e densidade de vegetação, além do desenvolvimento das culturas anuais de verão. Consequentemente, os fatores de ajuste para o substrato do dossel 0,5 e 1,0, recomendados para médias e baixas coberturas vegetais, tornam-se ineficientes na estimativa da cobertura vegetal e de seus parâmetros biofísicos nos índices de vegetação, tendo como resultado o agrupamento de diferentes tipos de vegetação e outras classes de uso do solo com assinaturas espectrais distintas na mesma classe, pois possuem valores SAVI próximos ou semelhantes.

A Tabela 6 apresenta os parâmetros média, desvio padrão e valores mínimo e máximo para os índices de vegetação NDVI e SAVI obtidos da imagem Landsat-5 TM em 07-01-2009, não considerando a divisão em classes de valores e o recorte do limite do município.

Tabela 6. Média, desvio padrão e valores máximo e mínimo dos índices NDVI e SAVI do município de Santa Cruz do Rio Pardo - SP em 07-01-2009

\begin{tabular}{l|cccc}
\hline & Média & $\begin{array}{c}\text { Desvio } \\
\text { padrão }\end{array}$ & Mínimo & Máximo \\
\hline NDVI & 0,472 & 0,155 & -1 & 1 \\
SAVI- -0,25 & 0,439 & 0,139 & $-0,495$ & 0,879 \\
SAVI- 0,5 & 0,37 & 0,121 & $-0,483$ & 0,866 \\
SAVI-1,0 & 0,31 & 0,105 & $-0,48$ & 0,85 \\
\hline
\end{tabular}

Elaboração: Demarchi (2009)

Da análise da tabela acima, infere-se que o índice de vegetação NDVI apresenta maior desvio padrão e, portanto, maior variabilidade dos dados em relação à média. Embora a quase totalidade dos valores NDVI esteja no intervalo de 0 a $<0,8$, há valores entre seu limite máximo e mínimo $(-1,0$ e 1,0).

Entre os índices de vegetação considerados, é o que apresenta classe 
modal de menor valor. Portanto, o índice NDVI é o que melhor representa as diferenças de vegetação na imagem de satélite tomada em 07-01-2009, seguido do índice SAVI - fator de ajuste para o substrato do dossel 0,25 , que apresenta distribuição dos resultados parecida, denotando a pequena influência do fator solo na reflectância dos alvos.

A Figura 7 mostra os valores NDVI e SAVI - fatores de ajuste do substrato do dossel 0,25, 0,5 e 1,0 do município de Santa Cruz do Rio Pardo SP calculados a partir da imagem Landsat-5 TM tomada em 29-04-2009.

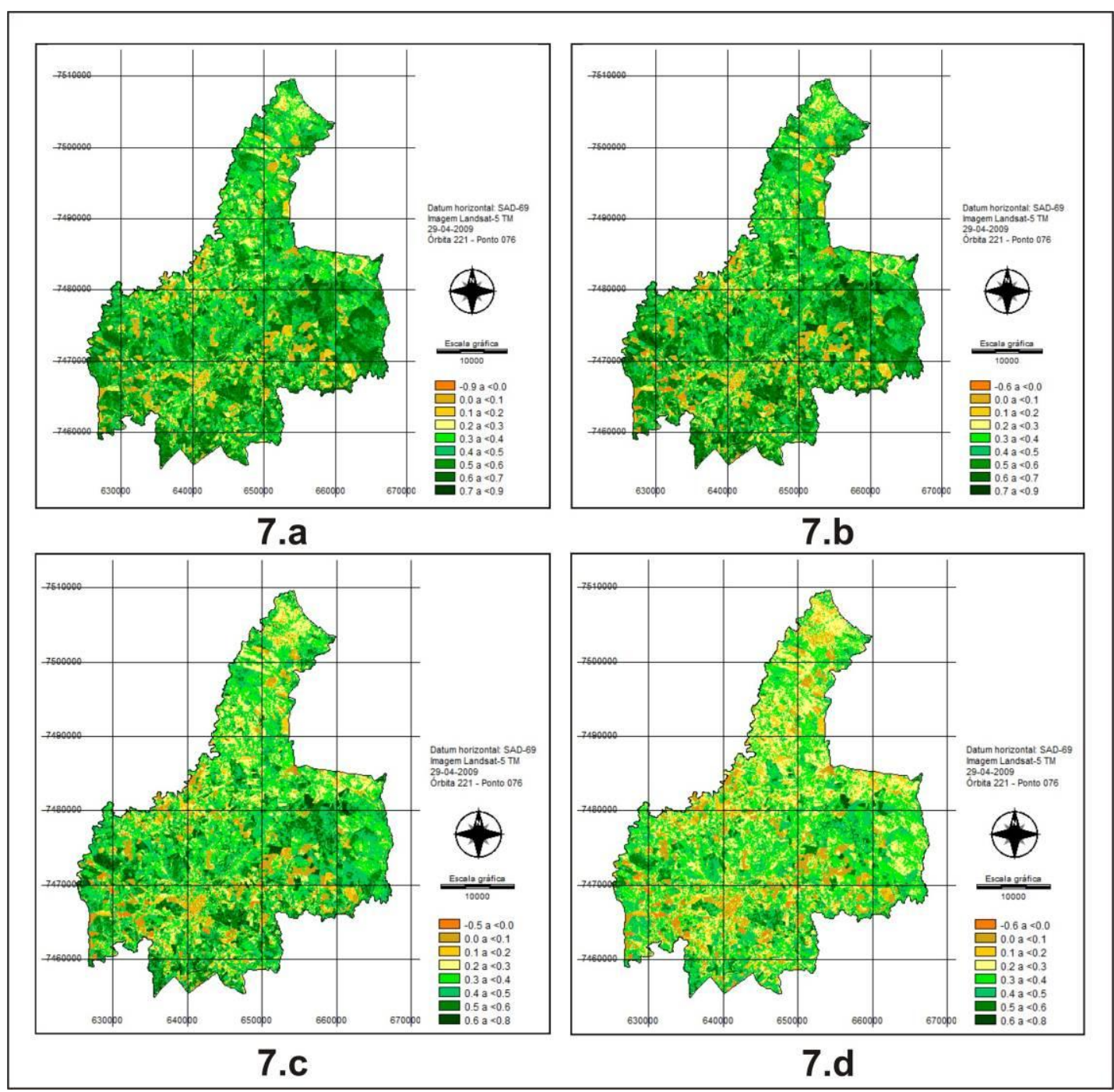

Figura 7. Santa Cruz do Rio Pardo: 7.a. Imagem NDVI; 7.b. Imagem SAVI fator de ajuste para o substrato do dossel 0,25; 7.c. Imagem SAVI - fator de ajuste para o substrato do dossel 0,$5 ; 7 . d$. Imagem SAVI - fator de ajuste para o substrato do dossel 1,0, em 29-04-2009 Elaboração: Demarchi (2009) 
A análise da imagem NDVI de 29-04-2009 e de suas classes de área permite chegar às seguintes constatações: os valores NDVI concentram-se no intervalo 0 e 0,8, que agrupam tanto solo exposto, solos de cobertura reduzida quanto mata nativa e culturas de médio e alto vigor vegetativo. Os valores negativos respondem por apenas $0,36 \%$ da área total do município. O intervalo de 0 a $<0,3$ reúne as classes de solo exposto, sendo que os solos de aspecto mais escuro (roxo escuro e rosa escuro) apresentam valores menores, e os solos mais claros, valores mais elevados. A área total ocupada por este intervalo é de 19,85 \%. O intervalo 0,3 a <0,4 agrupa solo exposto, áreas de pastagem e culturas anuais recém-cultivadas, abrangendo 17,63\% da área do município, e o intervalo 0,4 a <0,5, pastagens mais densas, culturas anuais e cana-de-açúcar, representando $24,32 \%$ da área do município. O intervalo 0,5 a $<0,6$ agrupa áreas cultivadas com cana-de-açúcar de média densidade de cobertura vegetal, pomares de laranja e algumas culturas anuais, perfazendo $23,44 \%$ da área do município. Já o intervalo seguinte $(0,6$ a $<0,7)$ reúne os cultivos de cana-de-açúcar de elevado vigor vegetativo e matas nativas, enquanto o intervalo 0,7 a $<0,9$ representa apenas as áreas de maior densidade de mata nativa.

Novamente, a cana-de-açúcar e as culturas anuais foram dispostas em várias classes de uso do solo, por apresentarem diferentes respostas espectrais conforme o estágio de desenvolvimento e o tipo de cultura.

O índice SAVI - fator de ajuste para o substrato do dossel 0,25, recomendado para áreas de cobertura vegetal densa, apresentou resultados semelhantes ao índice NDVI da mesma data. O intervalo de -0,1 a 0,8 compreende 99,77 \% da área do município, e as áreas das classes SAVI são bem próximas às áreas das classes NDVI. No intervalo $-0,1$ a $<0,3$ estão as áreas de solo exposto; entre 0,3 e <0,4, as áreas de culturas recém-cultivadas e solo exposto, e entre 0,4 e <0,5, as pastagens, cultivo de laranja e culturas anuais. $O$ intervalo de 0,5 a $<0,6$ agrupa as áreas de mata nativa, laranja, cana-de-açúcar e culturas anuais. O intervalo de 0,6 a <0,7 agrupa os usos mata nativa e cana-de-açúcar de maior vigor vegetativo; e o intervalo de 0,7 a 
$<0,9$, mata nativa e as lavouras de cana-de-açúcar de máximo vigor vegetativo e densidade de cobertura. Quanto à distinção dos alvos, o índice SAVI - 0,25 se mostrou menos eficiente que o índice NDVI para diferenciar as áreas de mata nativa, mas teve a mesma eficiência na distinção das classes de solo exposto e cana-de-açúcar de maior vigor vegetativo.

O índice SAVI - fator de ajuste para o substrato do dossel 0,5, recomendado para áreas de densidade média de vegetação, concentrou 99,81 $\%$ da área do município entre as classes $-0,1$ e $<0,7$, com resultados próximos ao índice anterior, porém concentrados nas classes 0,3 a $<0,4$ e 0,4 a $<0,5$, de maior freqüência, que juntas perfazem 51,21 \% da área do município e reúnem usos diferentes do solo na mesma classe. O primeiro intervalo agrupa solo recém-cultivado, laranja, culturas anuais e cana-de-açúcar, e o segundo, mata nativa, cana-de-açúcar e culturas anuais.

Por fim, o índice SAVI - fator de ajuste para o substrato do dossel 1,0, utilizado em áreas de cobertura vegetal de baixa densidade, agrupa ainda mais os resultados nas classes de valores intermediários, dificultando a distinção dos usos do solo. O intervalo 0,2 a $<0,5$ representa $73,96 \%$ da área do município. Já os alvos de valores SAVI baixos (solo exposto) e altos (mata nativa e cana-de-açúcar de elevado vigor vegetativo) são distinguidos dos demais em classes separadas. Como a cobertura vegetal do município nesta data é de $72,43 \%$, conforme cálculo realizado a partir da classificação supervisionada da imagem Landsat-5, os índices SAVI com fatores 0,5 e 1,0 mostraram-se ineficientes para detectar as diferenças de vegetação, agrupando respostas espectrais diferentes em intervalos de classe semelhantes.

A Tabela 7 apresenta a média, desvio padrão e valores mínimo e máximo das imagens NDVI e SAVI do dia 29-04-2009, calculados a partir das imagens não repartidas em classes e sem o recorte do limite do município. 
Tabela 7. Média, desvio padrão e valores máximo e mínimo dos índices NDVI e SAVI do município de Santa Cruz do Rio Pardo - SP em 29-04-2009

\begin{tabular}{l|cccc}
\hline Índices & Média & Desvio padrão & Mínimo & Máximo \\
\hline NDVI & 0,421 & 0,16 & -1 & 0,88095 \\
SAVI-0,25 & 0,432 & 0,168 & $-0,534$ & 0,901 \\
SAVI-0,5 & 0,36 & 0,148 & $-0,519$ & 0,854 \\
SAVI-1,0 & 0,305 & 0,129 & $-0,537$ & 0,813 \\
\hline
\end{tabular}

Elaboração: Demarchi (2009)

A partir da análise da referida Tabela, recomenda-se o uso das imagens NDVI e SAVI - fator de ajuste para o substrato do dossel 0,25, que apresentam intervalos maiores entre o valor mínimo e o máximo e maior desvio padrão, o que denota maior variabilidade dos dados em relação à média e maior capacidade de distinção dos alvos segundo as classes utilizadas.

Comparando o desempenho das classificações supervisionadas MAXVER realizadas e os índices de vegetação utilizados com os resultados obtidos por Pisani et al. (2009), é possível destacar que os índices NDVI e SAVI também apresentaram transição gradual entre os diferentes usos do solo, porém, não foi possível distinguir determinadas classes por meio de intervalos de valores, já que eles são grandes e coincidem com os de outras classes, principalmente cana-de-açúcar e culturas anuais. As classificações supervisionadas MAXVER também apresentaram problemas de identificação das classes e não foram sensíveis às transições entre as mesmas, dado seu caráter pixel-pixel. A tal fato, soma-se a resolução espacial da imagem, que dificultou a distinção de bordas.

A Tabela 8 compara a porcentagem de cobertura vegetal do município de Santa Cruz do Rio Pardo - SP calculadas para os métodos classificação supervisionada MAXVER, NDVI e SAVI - fator de ajuste para o substrato do 
dossel 0,25 , julgado o mais adequado para as imagens de satélite abordadas neste trabalho. Para o cálculo da cobertura vegetal através dos índices NDVI e SAVI, foram utilizadas as classes que reúnem desde baixa cobertura vegetal, como as pastagens, até as culturas de maior vigor vegetativo e mata nativa.

Tabela 8. Porcentagem de cobertura do solo do município de Santa Cruz do Rio Pardo - SP segundo o método de classificação supervisionada MAXVER e os índices de vegetação NDVI e SAVI - fator 0,25

\begin{tabular}{l|ccc}
\hline Métodos & $\mathbf{2 6 - 0 5 - 2 0 0 7}$ & $\mathbf{0 7 - 0 1 - 2 0 0 9}$ & 29-04-2009 \\
\hline Classificação Maxver & 83,91 & 80,41 & $\mathbf{7 2 , 4 3}$ \\
NDVI & 81,47 & 90,55 & $\mathbf{7 9 , 7 8}$ \\
SAVI - fator 0,25 & 80,69 & 89,09 & 79,34 \\
\hline
\end{tabular}

Elaboração: Demarchi (2009)

Embora as classes consideradas no cálculo da porcentagem de cobertura vegetal do índice de vegetação NDVI de 07-01-2009 e 29-04-2009 agrupem solo exposto e áreas de pastagem e baixa cobertura vegetal, o que interferiu no resultado, os valores de porcentagem de cobertura vegetal nos índices NDVI e SAVI são próximos, mas discrepantes em relação ao valor obtido pelo método da classificação supervisionada por máxima verossimilhança.

\section{CONSIDERAÇÕES FINAIS}

Após a realização das etapas propostas neste trabalho, constata-se que:

- A classificação supervisionada por máxima verossimilhança apontou mudanças significativas na cobertura vegetal do solo, com destaque para 0 aumento das áreas de solo exposto e redução das áreas de pastagens, além do aumento da área cultivada com cana-de-açúcar, e mínima alteração das áreas ocupadas por culturas anuais; 
- O coeficiente Kappa mostrou-se ora discrepante, ora com resultados bastante próximos para a mesma classificação supervisionada, nos dois esquemas de amostragem utilizados (Random e Systematic), e com valores inversos em classificações diferentes. Seus resultados atestam classificações "boas" e "muito boas". De maneira geral, a classificação da imagem do dia 0701-2009 apresentou melhor exatidão no mapeamento, seguida da classificação da imagem de 29-04-2009, que apresentou exatidão intermediária;

- Os índices de vegetação NDVI e SAVI com fator de ajuste para o substrato do dossel 0,25 se mostraram semelhantes e adequados na determinação das diferenças de vegetação da área de estudo quanto à densidade de cobertura e vigor vegetativo, visto que a cobertura vegetal do município é relativamente alta, enquanto os índices SAVI com fatores 0,5 e 1,0 reuniram diferentes níveis de cobertura vegetal e assinaturas espectrais em intervalos menores, o que reduziu sua eficiência;

- O fatiamento das imagens NDVI e SAVI foi suficiente para a avaliação da aplicação desses índices, mas agrupou alvos diferentes, de respostas espectrais próximas, na mesma classe;

- Os valores de porcentagem de cobertura vegetal mostraram-se semelhantes para os índices de vegetação NDVI e SAVI, mas um tanto discrepantes da porcentagem de cobertura vegetal estimada pelo método da classificação supervisionada por máxima verossimilhança. É necessário destacar, porém, que estes valores são apenas estimativas, pois os mapas gerados por classificação supervisionada não são totalmente exatos, e o fatiamento dos índices de vegetação agrupou algumas áreas de solo exposto e outras de baixa cobertura vegetal no mesmo intervalo de classe;

- Os recortes espacial e temporal utilizados foram suficientes para o desenvolvimento deste trabalho. Porém, o uso de imagens de satélite dos meses de julho e agosto, meses mais secos do ano, indisponíveis no catálogo de imagens Landsat consultado para a área de estudo, poderia trazer 
resultados mais precisos na comparação entre a cobertura vegetal nos períodos seco e chuvoso.

\section{REFERÊNCIAS BIBLIOGRÁFICAS}

CRÓSTA, A. P. Processamento digital de imagens de sensoriamento remoto. Campinas: IG/UNICAMP, 1993. 170 p.

EASTMAN, J. R. Idrisi Andes: Guide to GIS and Image Processing. Worcester, MA: Clark University, 2006. 327 p.

ELMORE, A. J. et al. Quantifying vegetation change in semiarid environments: precision and accuracy of Spectral Mixture Analysis and the Normalized Difference Vegetation Index. Remote Sensing of Environment, v. 73, n.1, p.87-102, Jan. 2000

FONSECA, L. M. G. Processamento Digital de Imagens. São José dos Campos: Instituto Nacional de Pesquisas Espaciais, 2002 (apostila).

FUNDAÇÃO INSTITUTO BRASILEIRO DE GEOGRAFIA E ESTATÍSTICA. Cidades@. Disponível em: <http://www.ibge.gov.br/cidadesat/topwindow.htm?1>. Acesso em 05dez. 2009.

FUNDAÇÃO INSTITUTO BRASILEIRO DE GEOGRAFIA E ESTATÍSTICA. Manual Técnico da Vegetação Brasileira. Rio de Janeiro: IBGE, 1992 (Série Manuais Técnicos em Geociências).

FUNDAÇÃO INSTITUTO BRASILEIRO DE GEOGRAFIA E ESTATÍSTICA. Mapa da Vegetação do Brasil. Rio de Janeiro: IBGE, 2004.

GURGEL, H. C. Variabilidade especial e temporal do NDVI sobre o Brasil e suas conexões com o clima. São José dos Campos, 2000. 118 f. Dissertação (Mestrado em Sensoriamento Remoto) - Instituto Nacional de Pesquisas Espaciais.

HUETE, A. R. A Soil-Adjusted Vegetation Index (SAVI). Remote Sensing of Environment, v. 25, n. 3, p.205-309, Aug. 1988.

INSTITUTO BRASILEIRO DE GEOGRAFIA. Superintendência de Cartografia. Plano Cartográfico do Estado de São Paulo. Município de Santa Cruz do Rio Pardo. Folhas: Domélia, SF-22-Z-B-IV-1; Ipauçu, SF-22-Z-C-III-2; Óleo, SF22-Z-B-IV-3; Ourinhos, SF-22-Z-A-VI-3; Santa Cruz do Rio Pardo, SF-22-ZA-VI-4 e São Pedro do Turvo (folha SF-22-Z-A-VI-2). São Paulo, Escala 1:50.000, 1973.

INSTITUTO NACIONAL DE PESQUISAS ESPACIAIS. Catálogo de imagens Landsat-5. Disponível em: <http://www.inpe.br>. Acesso em 2nov.2009.

INSTITUTO NACIONAL DE PESQUISAS ESPACIAIS. Spring: Tutorial de Geoprocessamento: Classificação de imagens. Disponível em: $<$ http://www.dpi.inpe.br/spring/portugues/tutorial/classific.html>. Acesso em 04dez.2009. 
JENSEN, J. R. Sensoriamento Remoto da Vegetação. In:

Sensoriamento remoto do ambiente: uma perspectiva em recursos terrestres. Tradução: José Carlos Neves Epiphanio (coord.) et al. São José dos Campos: Parêntese, 2009. p.357-410.

KNIPLING, E. B. Physical and Physiological Basis for the Reflectance of Visible and Near-Infrared Radiation from Vegetation. Remote Sensing of Environment. v. 1, n.3, p.155-159, Fev. 1970.

LANDIS, R.; $\mathrm{KOCH}$, G. G. The measurement of observer agreement for categorical data. Biometrics, v.33, n.1, p.159-174, Mar. 1977.

MIRANDA, M.J. et al. A classificação climática de Köeppen para o Estado de São Paulo. Disponível em: <http://www.cpa.unicamp.br/outrasinformacoes/clima-dos-municipios-paulistas.html>. Acesso em 05dez.2009.

MOREIRA, M. A. Fundamentos de Sensoriamento Remoto e Metodologias de Aplicação. 1.ed. São José dos Campos: Instituto Nacional de Pesquisas Espaciais, 2001. 250 p.

NOVO, E. M. L. M. Sensoriamento remoto: princípios e aplicações. 2.ed. São Paulo: Edgar Blücher, 1992. 308 p.

OLIVEIRA, J. B. Solos do Estado de São Paulo: descrição das classes registradas no mapa pedológico. Campinas, Boletim Científico 45. 1999. $112 \mathrm{p}$.

PISANI, R. J. et al. Análise comparativa entre o método de classificação supervisionada Maxver e NDVI para classes de uso do solo. In: X Congreso Argentino de Ingeniería Rural y II del Mercosur, 2009. Rosário: UNR Editora, 2009. v. 1. p.1681-1684.

ROSA, R. Introdução ao Sensoriamento Remoto. 7.ed. Uberlândia: EDUFU, 2009. 264 p.

ROSENFIELD, G. H.; FITZPATRICK-LINS, K. A coefficient of agreement as a measure of thematic classification accuracy. Photogrammetric Engineering and Remote Sensing, v.52, n.2, p.223-227, Fev. 1986.

ROSS, J. L. S.; MOROZ, I. C. Mapa geomorfológico do Estado de São Paulo. São Paulo: FFLCH-USP, 1997, p.41-2. Escala 1:500.000.

SÃO PAULO. Mapa das Unidades Hidrográficas de Gerenciamento de Recursos Hídricos - UGRHI. São Paulo: IGC, 1996. Escala 1:1.000.000.

SIMÕES, L. B. Integração entre um modelo de simulação hidrológica e sistema de informação geográfica na delimitação de zonas tampão ripárias. Botucatu, 2001. $185 \mathrm{f}$. Tese (Doutorado em Agronomia/Energia na Agricultura) - Faculdade de Ciências Agronômicas, Universidade Estadual Paulista.

WANG, Q.; ADIKU, S.; TENHUNEN, J.; GRANIER, A. On the relationship of NDVI with leaf area index in a deciduous forest site. Remote Sensing of Environment, v. 94, n.2, p.244-255, Jan. 2005. 